Tjalling C. Koopmans Research Institute Tpllizh. Aoopmen

Discussion Paper Series nr: 13-02

\title{
Cross-Country Private Saving Heterogeneity and Culture
}

\author{
M. de Castro Campos \\ C. Kool \\ J. Muysken
}




\section{Tjalling C. Koopmans Research Institute Utrecht School of Economics Utrecht University}

Kriekenpitplein 21-22

3584 EC Utrecht

The Netherlands

telephone $\quad+31302539800$

fax +31302537373

website www.koopmansinstitute.uu.nl

The Tjalling C. Koopmans Institute is the research institute and research school of Utrecht School of Economics.

It was founded in 2003, and named after Professor Tjalling C. Koopmans, Dutch-born Nobel Prize laureate in economics of 1975.

In the discussion papers series the Koopmans Institute publishes results of ongoing research for early dissemination of research results, and to enhance discussion with colleagues.

Please send any comments and suggestions on the Koopmans institute, or this series to J.M.vanDort@uu.nl

ontwerp voorblad: WRIK Utrecht

\section{How to reach the authors}

Please direct all correspondence to the first author.

\section{M. de Castro Campos}

C. Kool

Utrecht University

Utrecht School of Economics

Kriekenpitplein 21-22

3584 TC Utrecht

The Netherlands.

E-mail: M.deCastroCampos@uu.nl

J. Muysken

C.J.M.Kool@uu.nl

University of Maastricht

School of Business and Economics

P.O. Box 616

6200 MD Maastricht

the Netherlands

E-mail: j.muysken@maastrichtuniversity.nI

This paper can be downloaded at: http://

www.uu.nl/rebo/economie/discussionpapers 
Utrecht School of Economics

Tjalling C. Koopmans Research Institute

Discussion Paper Series 13-02

\title{
Cross-Country Private Saving Heterogeneity and Culture
}

\author{
M. de Castro Campos \\ C. Koola \\ J. Muysken ${ }^{b}$ \\ ${ }^{a}$ Utrecht School of Economics \\ Utrecht University \\ ${ }^{\mathrm{b}}$ School of Business and Economics \\ University of Maastricht \\ March 2013
}

\begin{abstract}
Motivated by the dominant role of cross-country heterogeneity in private saving in the creation of Eurozone imbalances over the past decade, we empirically investigate the determinants of private saving for a sample of 30 OECD countries over the period 1990-2010. In addition to standard macroeconomic variables, we include three country-specific cultural indicators, derived from theWorld and European Value Surveys. We find these three variables - thrift, trust and religiosity - to significantly contribute to the explanation of cross country saving heterogeneity both for the OECD group at large and for the Eurozone countries separately.
\end{abstract}

Keywords: culture, institutions, current account, Eurozone imbalances

JEL classification: 047, 030, D24, C24 


\title{
Cross-Country Private Saving Heterogeneity and Culture
}

\author{
M. de Castro Campos ${ }^{\mathrm{a}, *}$, C. Kool ${ }^{\mathrm{a}}$, J. Muysken ${ }^{\mathrm{b}}$ \\ ${ }^{a}$ Utrecht School of Economics, Utrecht University, Kriekenpitplein 21-22, 3584 EC, \\ Utrecht, the Netherlands \\ ${ }^{b}$ University of Maastricht, P.O. Box, 6166200 MS Maastricht, the Netherlands
}

\begin{abstract}
Motivated by the dominant role of cross-country heterogeneity in private saving in the creation of Eurozone imbalances over the past decade, we empirically investigate the determinants of private saving for a sample of 30 OECD countries over the period 1990-2010. In addition to standard macroeconomic variables, we include three country-specific cultural indicators, derived from the World and European Value Surveys. We find these three variables - thrift, trust and religiosity - to significantly contribute to the explanation of cross country saving heterogeneity both for the OECD group at large and for the Eurozone countries separately.
\end{abstract}

Keywords: culture, institutions, current account, Eurozone imbalances JEL: O47, O30, D24, C24

${ }^{*}$ Corresponding author.

Email addresses: M.deCastroCampos@uu.nl (M. de Castro Campos), C.J.M.Kool@uu.nl (C. Kool), j.muysken@maastrichtuniversity.nl (J. Muysken) 


\section{Introduction}

The introduction of the euro in 1999 was assumed to lead to macroeconomic convergence between the countries participating in the eurozone. In practice, imbalances between euro area countries have systematically grown in the first decade of the euro's existence. Holinski et al. (2012) and Jaumotte and Sodsriwiboon (2010) empirically document divergent developments in competitiveness as well as the emergence of large accumulated current account surpluses in the Northern part of the eurozone and deficits in the Southern part. In addition, these authors show that persistent current account imbalances within the eurozone are primarily due to cross-country heterogeneity in gross private saving. In this paper, we empirically investigate the determinants of cross-country saving to shed more light on the heterogeneity between countries in general and between eurozone countries in particular. In addition to the macroeconomic explanatory variables that are typically used in the literature, we add a few institutional and cultural variables as potential drivers of cross-country differences. It turns out that these variables have a significant impact in explaining the cross-country heterogeneity.

The macroeconomic determinants of private saving have been extensively studied in the past. Examples are Schmidt-Hebbel et al. (1992) and Edwards (1996), who focus on developing countries and on Latin America, respectively. Masson et al. (1998), Hussein and Thirlwall (1999) and Loayza et al. (2000), include both industrial and developing countries. Finally Kessler et al. (1993), Haque et al. (1999), De Serres and Pelgrin (2002) and Ramajo et al. (2006) study the OECD countries, whereas Hondroyiannis (2006) exclusively take European countries into account. Generally speaking, all of these studies include measurements for income, inflation, uncertainty, fiscal policy, demographics, growth and foreign borrowing constraints as explanatory variables. Depending on the focus of the study, other variables may have been included as well. ${ }^{1}$ Empirically, different methods are used, including cross-section analysis, panel analysis with static fixed effects (Masson et al., 1998), instrumental variables (Edwards, 1996; Loayza et al., 2000), pooled mean group estimation (Haque et al., 1999) and cointegration (Hondroyiannis, 2006).

To our knowledge, empirical evidence on the relationship between private

\footnotetext{
${ }^{1}$ Loayza et al. (2000) contains an overview of specifications and empirical results.
} 
saving and cultural variables is scarce. ${ }^{2}$ Carroll et al. (1994) and Carroll et al. (1999) investigate saving differences among immigrants in Canada. Al-Awad and Elhiraika (2003) look into saving behavior of immigrants in the United Arab Emirates (UAE). Although none of these analyses find conclusive results, they claim that by looking at immigrants, they are able to capture the effect of cultural background on saving. ${ }^{3}$ Guiso et al. (2006) take a broader approach and investigate the effect of various cultural variables on a set of endogenous economic variables. They provide suggestive evidence of a positive relation between thrift and national saving. ${ }^{4}$

In this paper, we contribute to the literature on the determinants of private saving by including cultural effects in addition to the standard macroeconomic variables. Focusing on the eurozone, we are simultaneously able to increase our understanding of cross- country heterogeneity and divergence. To increase the statistical power of our analysis, we use a set of thirty OECD countries in our estimations. We use annual data for the period 1990-2010. For the macroeconomic variables we gathered data from AMECO, IMF, World Bank and Lane and Milesi-Ferretti (2007). Our cultural and institutional variables are obtained from the European and the World Value Surveys.

This paper is set up as follows. In Section 2, we provide a brief overview of savings and investment heterogeneity for the eurozone countries. In Section 3 , we discuss the data and the methodology employed in this paper. We present our results in Section 4 and conclude in Section 5.

\section{European Union imbalances}

To discuss cross-country saving and investment heterogeneity in the eurozone, we follow Holinski et al. (2012) and use the national account incomeexpenditure identity, which states that gross national saving - the current account - equals the sum of net private saving and net public saving. Similar

\footnotetext{
${ }^{2}$ See Beugelsdijk and Maseland (2011) for an introduction on the development of culture as an area of study within the science of economics.

${ }^{3}$ See also e.g. Algan and Cahuc (2007), Algan and Cahuc (2010), and Fernández (2010).

${ }^{4}$ Related work by Barro and McCleary (2003), Mangeloja (2005), and McCleary and Barro (2006) uses religion as a measurement of culture in order to investigate its effect on economic outcomes. Knack and Keefer (1997), Acemoglu et al. (2001) and Tabellini (2010) are examples of more general institutional determinants on economic performance. See Efendic et al. (2010) for an overview.
} 
to Holinski et al. (2012), we divide the eurozone countries in a Northern and a Southern group. ${ }^{5}$

Figure 1 shows that, on one hand, the Northern group had a consistent and gradually rising current account surplus from the late 1990s till 2007. The Southern countries, on the other hand, faced a consistently growing current account deficit over the same period. Since the start of the global financial crisis, these trends have been reversed, but the gap in current account balances is still sizable. Figures 2 and 3 demonstrate that most of the cross-country dynamics in saving and investment come from the Southern countries and, more particularly, from the development in Southern private saving. To a lesser extent, Southern investment is seen to increase. Up until the start of the financial crises, government balances increase throughout the eurozone, though the Southern part is consistently lagging the Northern part. ${ }^{6}$

Figure 1: Current account

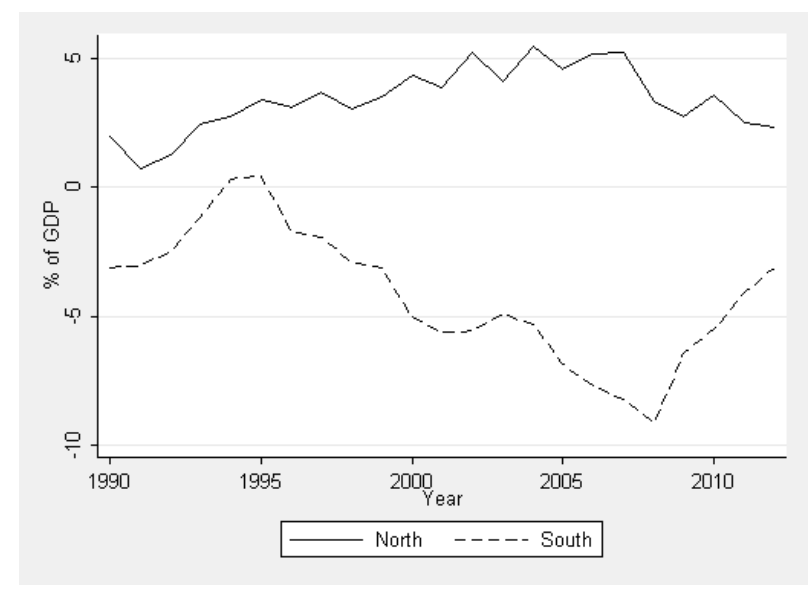

In our view, the evidence strongly suggests that a better understanding of the macroeconomic fundamentals of private saving is crucial. Potentially, standard macroeconomic variables - including the greater access to financial

\footnotetext{
${ }^{5}$ North is defined as Austria, Belgium, Finland, France, Germany, Luxembourg and the Netherlands; South is defined as Ireland, Italy, Greece, Portugal, Slovakia and Spain. Holinski et al. (2012) did not include Belgium, France and Luxembourg in North nor Italy and Slovakia in South.

${ }^{6}$ Similar evidence can be found in Jaumotte and Sodsriwiboon (2010).
} 
Figure 2: Net Saving
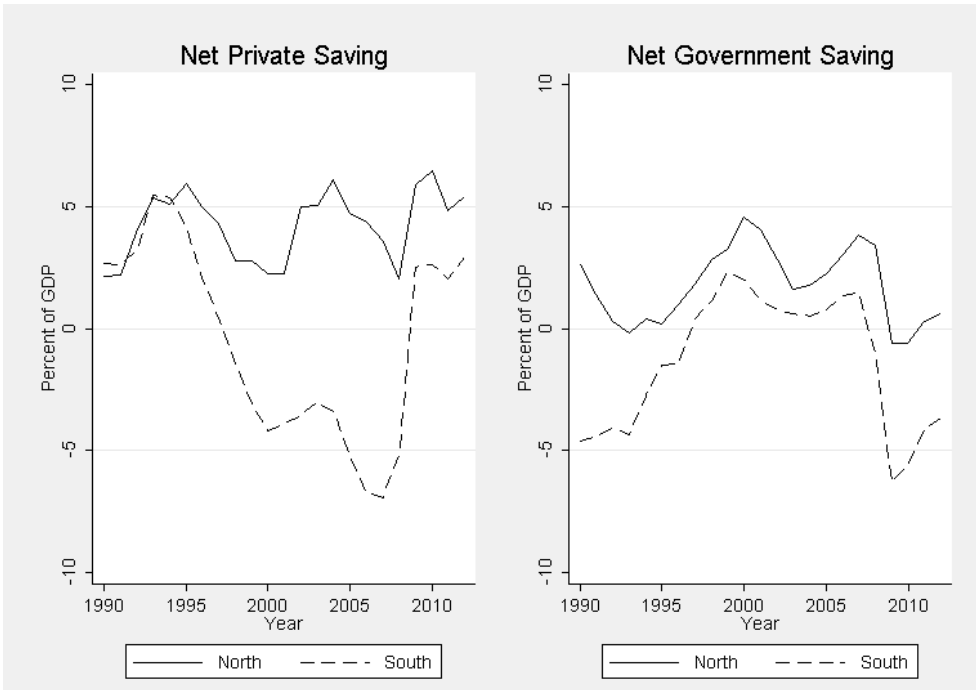

Figure 3: Private Saving and Investment
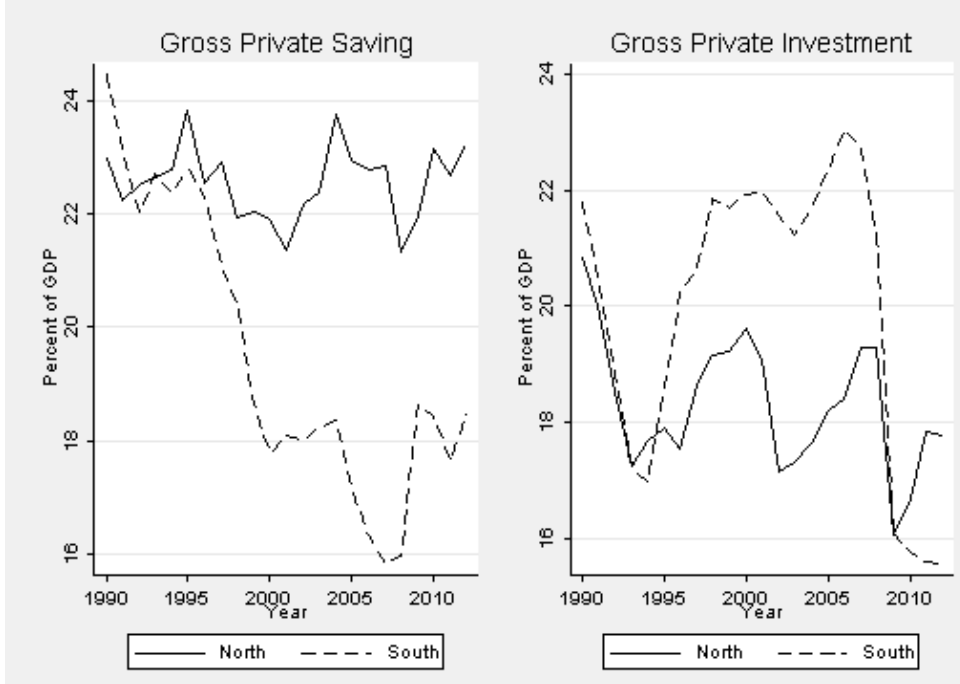
markets and the decrease of risk premiums for Southern countries as a result of the creation of the eurozone - may go a long way in explaining the observed developments. However, according to Jaumotte and Sodsriwiboon (2010) euro and EMU dummies that differentiate between North and South remain economically and statistically significant even when the obvious macroeconomic fundamentals are included. For this reason, we hypothesize that other variables that reflect cultural, behavioral and historical differences among the eurozone countries may play a significant role too, as already suggested by Holinski et al. (2012).

\section{Data and methodology}

In our analysis, we start with a base model that only includes standard macroeconomic variables. Subsequently, we extend the model in various directions, including cultural and institutional variables. Throughout the paper, we employ pooled ordinary least square (OLS), with the exception for one model where we employ fixed effect panel estimation. The main advantage of the first approach is that it allows us to include variables that have a small time variant component, as is the case for the cultural and institutional dummy variables. ${ }^{7}$ Additionally, we include time dummies to possibly control for business cycle movements of the macroeconomic data. To attempt to control for endogeneity, we use the lagged disposable income and the lagged net foreign assets instead of the variables themselves (Jaumotte and Sodsriwiboon, 2010). We expect these two variables to have an important role in determining the future level of private saving.

For our analysis we focus on the group of developed (OECD) countries ${ }^{8}$ - a list with countries is given in Table A.1 in the Appendix. We use annual data from AMECO, the IMF and the Worldbank for the macroeconomic variables over the sample period from 1990 until 2010 - see Table A.2 in the Appendix for more information. The data on foreign assets are obtained from Lane and Milesi-Ferretti (2007). Cultural and institutional variables

\footnotetext{
${ }^{7}$ Note that pooled OLS theoretically is unable to establish causality relations, but only provides evidence on the statistical relations between the dependent and the explanatory variables.

${ }^{8}$ As a robustness check, we replicated the analysis for all countries in the AMECO dataset, including the Eastern European countries and excluding all non-European countries. The results were qualitatively similar.
} 
are obtained from the European and World Value Surveys.

The variable private saving is constructed by subtracting public saving from total saving. Public saving is defined as current revenue minus current expenditure. Following Loayza et al. (2000) we use government budget $^{9}$, GDP growth, real disposable income, inflation, net foreign assets and the dependency ratio as macroeconomic explanatory variables. Private saving, government budget and net foreign assets are expressed in percentage of GDP; income is given in purchase power parity per capita; GDP and inflation are given in percentage growth rates while the dependency ratio is defined as the ratio of people below 15 and above 64 years old divided by the number of people between 15 and 65 years old, expressed as percentage.

We expect the private saving to partially offset the government deficit. The usual economic reasoning applies here: a higher deficit is followed by an increase in taxes or a cut in expenses and individuals anticipate that by increasing their savings. GDP growth may affect private saving through the income and the substitution effect. Which one dominates is dependent on the level of development of the country. Theoretically, inflation should have a positive effect on private saving. However, empirically the effect is not always so clear - see Loayza et al. (2000). ${ }^{10}$ A higher dependency ratio leads to lower aggregate saving since the rate of dissaving during retirement will be higher than the rate of saving by the working population.

Since private saving is directly linked with the current account, we also include net foreign assets. The effect of the net foreign assets is not straightforward. Economies with a high level of net foreign assets are able to run deficits and can afford to save less, yielding a negative effect. However, these economies also receive higher net-foreign income flows, which leads to a higher income and possibly, higher saving. The opposite holds for economies with low levels of net foreign assets. (Jaumotte and Sodsriwiboon, 2010)

The descriptive summary of the variables is given in Table 1. The corre-

\footnotetext{
${ }^{9}$ The government budget is defined as revenue minus expenditure. A difference exists between the government budget and public saving due to the inclusion of capital transfers in total revenue and total expenditure. We neglect this difference, as is usual in the literature.

${ }^{10}$ In the results presented here, we have left out possible interest rate effects. Preliminary results yielded small and negative coefficients, possibly due to endogeneity issues. Other studies have also found ambiguous results regarding this issue. See Masson et al. (1998). Moreover, especially for the interest rate missing observations are a serious problem.
} 
sponding correlation matrix is provided in Table A.3 in the Appendix. We assume the variables to be stationary and carefully checked for the occurrence of outliers. ${ }^{11}$

Table 1: Descriptive statistics

\begin{tabular}{|c|c|c|c|c|c|}
\hline variable & $\mathbf{N}$ & mean & sd & $\min$ & $\max$ \\
\hline Private saving & 573 & 20.582 & 4.822 & -4.396 & 34.537 \\
\hline Dependency ratio & 600 & 49.723 & 5.125 & 36.568 & 76.015 \\
\hline Income & 616 & 20.558 & 8.274 & 5.061 & 53.364 \\
\hline Inflation & 619 & 5.563 & 11.599 & -4.480 & 106.263 \\
\hline Government budget & 599 & -2.357 & 4.741 & -31.312 & 19.132 \\
\hline GDP growth & 623 & 1.884 & 2.948 & -11.152 & 10.411 \\
\hline Net foreign assets & 625 & -16.866 & 49.976 & -165.044 & 172.894 \\
\hline
\end{tabular}

Finally, we introduce three variables that potentially capture cultural and institutional factors, namely, thrift, trust and religiosity. These are obtained from the European Value Survey (EVS) for the European countries in our dataset and from the World Value Survey (WVS) for the non-European countries. Both datasets are cross-sectional and longitudinal studies that look into cultural values about beliefs, work, society, preferences and attitudes. Examples of economic research using the EVS or WVS are Knack and Keefer (1997), Guiso et al. (2006), McCleary and Barro (2006), Tabellini (2007) and Tabellini (2010). Typically, country-level cultural indicators are constructed as the average of individual responses per country. We follow the same approach, where for each variable we take the average across the different waves since 1990.

In the EVS and WVS, individuals are shown the following list of personal characteristics: good manners, politeness and neatness, independence, hard work, honesty, feeling of responsibility, patience, imagination, tolerance and respect for other people, leadership, self-control, thrift saving money and things, determination, perseverance, religious faith, unselfishness, obedience, loyalty and none. Afterwards, they were asked to choose those five characteristics that they consider most important to teach their children. We assume

\footnotetext{
${ }^{11}$ Using 3-year moving averages of our variables rather than annual observations did not lead to significantly different results.
} 
that people who find thrift an important characteristic to pass through their children tend to save more themselves. We define our variable thrift as the fraction of the population that has cited thrift in the list above. ${ }^{12}$ Thus, the variable is used here as a proxy for the inclination to save in a country. In Figure 4, we plot the average value of thrift per country versus average private saving. We expect higher levels of thrift to be positively associated with private saving. We can see from the figure that the relationship is positive.

Figure 4: Average Thrift per country

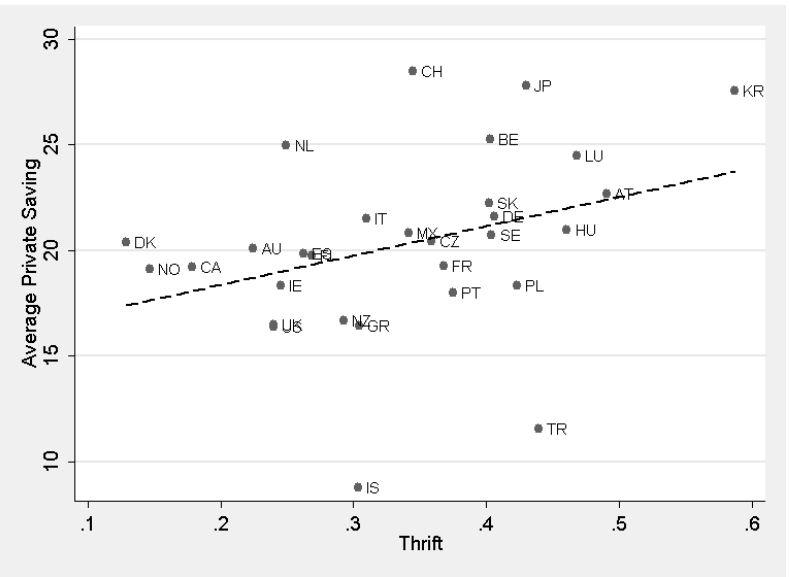

Second, we use a trust indicator in our analysis. We construct the trust variable based on the EVS/WVS question whether the person agrees with the sentence "on average, most people can be trusted". Our variable is the proportion of people that responded yes to this question. In our view, this can be interpreted more generally as the degree of trust in the country and the country's institutions (see for example North (1992)). Higher trust is associated with higher institutional quality, which in turn is hypothesized to lead to a higher private saving rate. In Figure 5, we show the average values for trust against average private saving per country. The relation is positive, though only marginally so.

The third indicator of cultural characteristics relates to the degree of religiosity. The underlying assumption is that participation in a religious group may foster religious beliefs such as hard work, honesty and ethics (McCleary

\footnotetext{
${ }^{12}$ This is similar to the approach taken by Guiso et al. (2003).
} 
Figure 5: Average trust per country

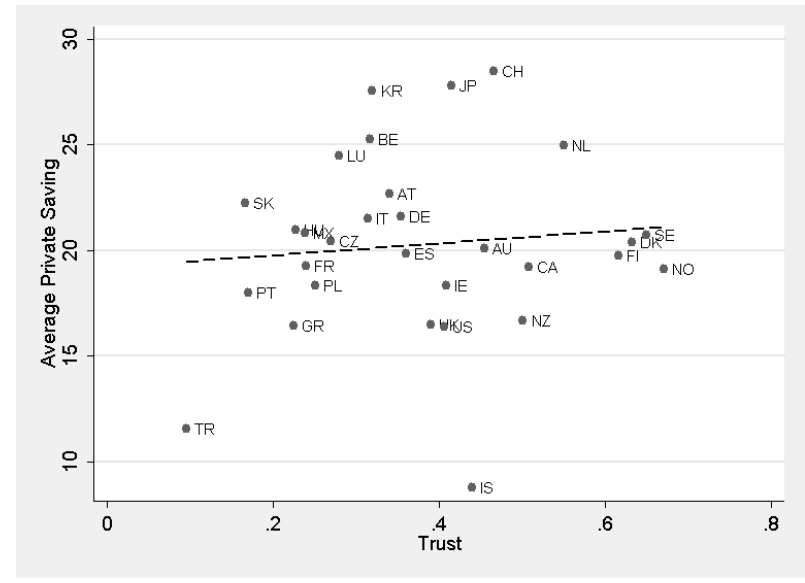

and Barro, 2006). These values might in turn increase economic performance and be positively related to saving. As before, the variable has been constructed on the basis of individual answers to questions in the EVS and WVS. Our religiosity indicator is an unweighted average of four variables measured in the EVS/WVS: being member of a religious community, believing in heaven, believing in hell, and visiting religious services more than once a month. ${ }^{13}$ In our view, these "indirect" measurements of religion probably give a better indication of the religious nature of people. By using four variables together, we expect to control for different facets of having a religion. Additionally, we believe that by grouping four different measures into the creation of one variable, we may be able to reduce self-reported bias. ${ }^{14}$ In Figure 6 we show the average ratio of our variable against private saving. Contrary to our basic hypothesis, the relation is negative.

Table A.4 in the Appendix provides the bilateral correlation matrix of the three cultural variables and private saving. As suggested by Figures 4 to 6 , saving is positively correlated with thrift and negatively with religiosity.

\footnotetext{
${ }^{13}$ The bilateral correlations between these four variables range from between 0.5 to 0.7 .

${ }^{14}$ Barro and McCleary (2003); McCleary and Barro (2006) use religious denomination as an indicator of religion. We prefer our own measure as first, many people are raised religiously, but have no formal contact with their church in real life leading to severe measurement error, while second the religious denomination measurement available in the EVS/WVS may not be representative for the country as a whole.
} 
Figure 6: Average religiosity per country

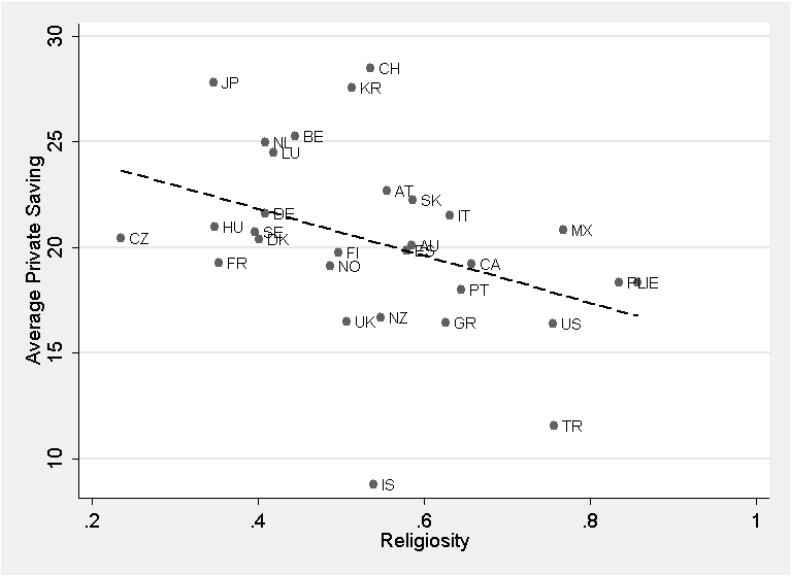

The correlation between trust and thrift is significantly negative.

\section{Results}

In this section we present and discuss the results, moving from a standard specification with macroeconomic determinants of private saving only, to extensions using euro dummies for North and South respectively, as well as variables reflecting cultural and institutional characteristics. Table 2 provides an overview of the results.

\subsection{EMU and euro dummies}

Our first goal is to investigate whether the diverging private saving behavior between North and South in the eurozone as displayed in Section 2 can be attributed to differences in underlying economic fundamentals or arises for other reasons. An example of the first effect would be the difference in income levels of these countries, as put forward by Jaumotte and Sodsriwiboon (2010). Alternatively, differences in private saving behavior can arise from non-economic factors, such as thrift or trust.

Columns (1) to (3) provide information on this issue. Column (1) contains the results for the pooled OLS regression for all thirty countries in our sample using the benchmark specification. The benchmark specification is 


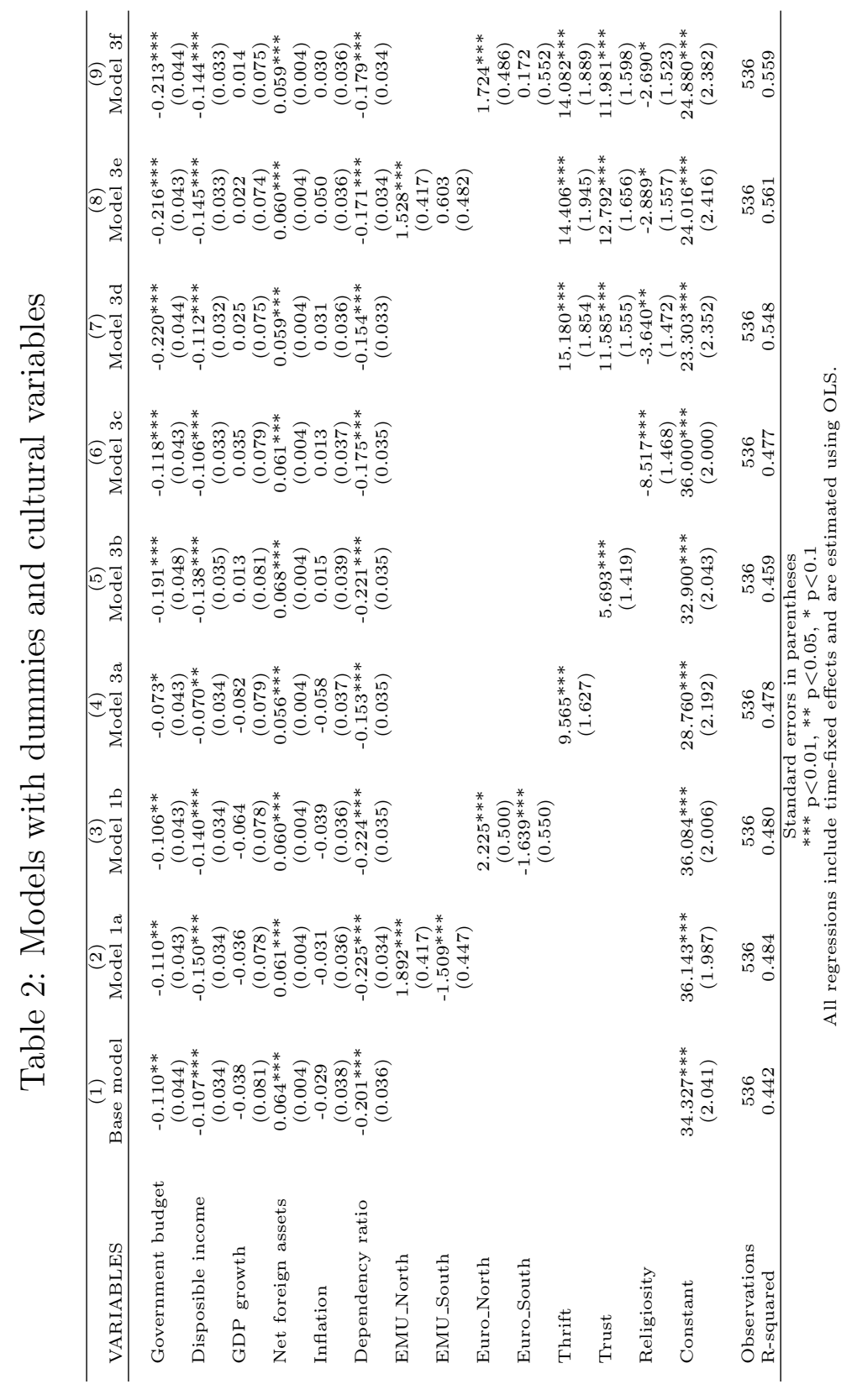


a simplified version of Jaumotte and Sodsriwiboon (2010) and contains a limited set of standard macroeconomic determinants of saving. ${ }^{15}$

In columns (2) and (3) we extend the benchmark specification with two dummy variables EMU North and EMU South, or two dummy variables Euro North and Euro South, respectively, similar to Jaumotte and Sodsriwiboon (2010). The dummy EMU North takes a value of 1 for each year a eurozone country in the North group is part of EMU, while the dummy Euro North takes a value of 1 for each year a eurozone country in the North group is part of the eurozone. The same procedure applies for the dummy variables EMU South and Euro South. ${ }^{16}$ To avoid multicollinearity, we do not include the two sets of dummies simultaneously. As we have mentioned in Section 2, we include Ireland in the South group, following Holinski et al. (2012). The main reason for our choice is that the current account and private saving developments in Ireland follow the typical pattern of Southern countries. Jaumotte and Sodsriwiboon (2010) on the other hand regard Ireland as part of North. As a sensitivity test analysis, we replicate our estimations both with Ireland in North and excluding Ireland from the sample. Overall, the results remain qualitatively unchanged.

A few points stand out from columns (1)-(3) in Table 2. First, with the exception of the coefficient for disposable income, the control variables have the predicted sign. ${ }^{17}$ The inflation and growth coefficients fail to reach significance, though. Second, inclusion of the EMU dummies (column 2) or Euro dummies (column 3) leaves the size and significance of the coefficients on the control variables unchanged. Third, EMU and Euro dummies are all significant with positive coefficients for the Northern eurozone countries and negative coefficients for the Southern eurozone countries. These results are in line with the qualitative findings shown in Section 2 as well as Holinski et al. (2012) and with the quantitative results in Jaumotte and Sodsriwiboon (2010). ${ }^{18}$ The significance of the EMU and Euro dummies provides sugges-

\footnotetext{
${ }^{15}$ In contrast with Jaumotte and Sodsriwiboon (2010), population growth, oil balance, a financial center dummy variable and a financial liberalization index are excluded.

${ }^{16}$ For an overview of when each country joined the EMU and the Euro, see Jaumotte and Sodsriwiboon (2010).

${ }^{17} \mathrm{We}$ also estimated the model including income squared to account for possible differences in the effects relative to the income level. However, the coefficient for income squared was insignificant.

${ }^{18}$ Similar but somewhat weaker results are found when using the AMECO data that
} 
tive evidence of the presence of other factors driving private saving than just the set of standard macroeconomic variables. In the next section, we therefore incorporate three alternative factors that reflect cultural and behavioral country characteristics in the regression.

\subsection{Cultural Variables}

In models 3a through 3c (columns 4-6) of Table 2, we report the results when instead of the EMU or Euro dummies, we include thrift, trust and religiosity respectively, while in model $3 \mathrm{~d}$ (column 7 ) we include all three cultural variables simultaneously. From model $3 \mathrm{a}$ we conclude that thrift has a highly significant positive coefficient. The significance of the control variables remains unchanged compared to the previous regressions, but the size of the control variable effects is reduced somewhat. Moreover, the overall explanatory power of the regression is higher than the benchmark and comparable in magnitude to the regressions that include the EMU and Euro dummies. The evidence suggests that thrift does provide independent explanatory power for differences in private saving behavior across the thirty OECD countries beyond the standard macroeconomic effects.

The results for trust are given in model 3b. A positive and significant effect is found, consistent with our hypothesis and with earlier evidence in Tabellini (2010). The additional explanatory power of trust compared to the benchmark equation is smaller than for thrift. The size and significance of the coefficients on the control variables remain roughly equal in the earlier models.

The results for religiosity are shown in model 3c. The coefficients of the control variables are very similar to the coefficients of the previous specifications. The coefficient of religiosity is significantly negative, implying that an increase in the degree of secularization is associated with higher levels of private saving. This is consistent with the bilateral correlation reported in Table A.4, but goes against our initial expectation that religion is associated with higher saving. ${ }^{19}$

include the Eastern European countries. However, in that case only the dummies for North are significant. This could be due to the similarities between South and Eastern Europe.

${ }^{19}$ When we use explicit religious denominations such as the ratio of Catholics and Protestants in society, we still find negative coefficients. This finding goes against Weber's theory. 
Finally, model 3d incorporates the three cultural variables simultaneously. We see that the coefficients increase in magnitude for thrift and trust, while for religiosity it decreases. All coefficients remain significant with the same sign as before. The overall explanatory power of the regression is about ten percentage points higher than the benchmark model. The size and significance of the control variables remains qualitatively unchanged.

In summary, we are able to show that the cultural variables individually and jointly significantly contribute to the explanation of cross-country differences in private saving across countries beyond the standard set of macroeconomic variables.

\subsection{Culture and eurozone divergence}

While regressions 3a-3d document the significant explanatory power of our cultural variables for private saving in general, they do not in themselves prove the economic and statistical importance of cultural effects as drivers of private saving divergence between Northern and Southern eurozone countries.

In columns 3e and 3f we explicitly focus on this issue by including both the three cultural variables as well as the EMU (model 3e) or Euro (model 3f) dummies in the regression. For both models the dummies for South substantially decrease in size and become insignificant. For North, no significant change in the dummy coefficients is seen. We interpret the result as suggestive evidence of the importance of cultural variables in the determination of private saving in general and of the divergence in private saving behavior between North and South in the eurozone in particular. Note that the fact that the main effect seems to come from the Southern countries corresponds with the observation in Section 2 that the divergence between North and South after the introduction of the euro is dominated by the dynamics of private saving in the South. Obviously, more research is required for a better understanding of our findings. Admittedly, our specification so far is limited to only three cultural variables where the literature suggests a wide range of potential institutional variables that may influence economic behavior and outcomes. ${ }^{20}$

Barro and McCleary (2003); McCleary and Barro (2006) report similar counter-intuitive effects of religion on growth. However, they do not provide a convincing explanation.

${ }^{20}$ E.g. Hofstede (2001); Demirguc-Kunt and Levine (2004). 


\subsection{Country effects}

In this section, we take an alternative route for the analysis of the crosscountry relation between private saving and cultural effects. Instead of a pooled regression model, we first do a panel estimation of the benchmark model 1 including country fixed effects. By definition, these country dummies capture all between variation, including possible cultural effects associated with private saving. ${ }^{21}$ In a second step we then relate the estimated fixed effects to our cultural variables thrift, trust, and religiosity.

Figure 7: Fixed country effects

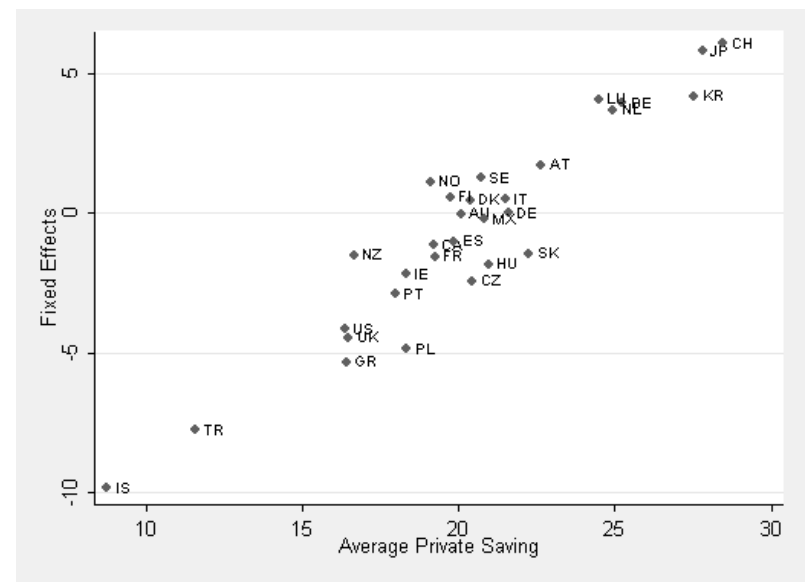

In Figure 7, we plot the estimated fixed effects against the average private saving rate per country. The benchmark country in the regression is Germany (fixed effect equal to zero). The most important message from Figure 7 is a clear clustering pattern with suggestive geographical and cultural characteristics. The Asian countries together with Switzerland are located in the upper right corner with high saving rates and country fixed effects. Turkey and Iceland are the biggest outliers in the lower left corner. Given the idiosyncratic saving behavior of these countries, the corresponding size of their fixed effects may not be too surprising. The variation in macroeconomic fundamentals may simply be insufficiently large to explain these large private saving differences.

\footnotetext{
${ }^{21}$ The coefficients on the control variables are qualitatively similar to the benchmark in Table 2. They are available upon request.
} 
In that respect, the clustering of the middle group with more normal saving rates in the range of 15 to 25 percent is more interesting. The Scandinavian countries and most of the Northern European countries form a joint cluster relatively high and to the right, while the Anglo-Saxon countries and the Southern European countries are relatively close together down and to the left. Focusing on the eurozone countries, we see that most of the Northern countries have positive fixed effects, while most of the Southern ones have negative fixed effects. Italy and France do not seem to comply perfectly with the hypothesized pattern. Note however that Holinski et al. (2012) using clustering techniques also fail to find strong evidence that Italy belongs to the Southern group. Neither do they provide clear-cut evidence that France belongs to the Northern group.

Overall, the clustering seems to follow well-known geographical and cultural patterns. As such, it provides suggestive evidence of an independent role for other than macroeconomic drivers of private saving differences.

In the second step, we therefore regress the estimated fixed effects on each of the cultural variables for the entire set of countries used in Section 2. Figures 8 through 10 graphically show the results. ${ }^{22,23}$ Consistent with our earlier evidence we find significant explanatory power for each of the cultural variables with respect to the estimated country fixed effects. For thrift and trust the impact is positive, for religiosity it is negative. Especially the relationships between the variables religiosity and trust and the country fixed effect are significant. The relationship with thrift is less strong. In our view, these graphs again are an indication of the potentially large role of cultural and institutional variables in explaining cross-country differences in economic outcomes. Furthermore, it is interesting to notice that specially in the Figures 9 and 10, we see that the countries from North and South cluster together. The clusters are less clear in the Figure 8.

\footnotetext{
${ }^{22}$ Detailed regression results are available on request from the authors. The p-value for the three cultural coefficients are zero.

${ }^{23}$ When we plot Figures 8 through 10 with only the European countries, we see that the fitted values' lines stay relatively unchanged. This confirms that the relationships we see represent all data and not only outliers.
} 
Figure 8: Thrift

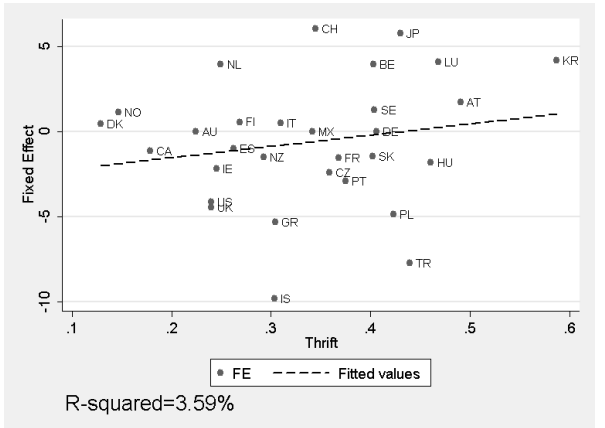

Figure 9: Trust

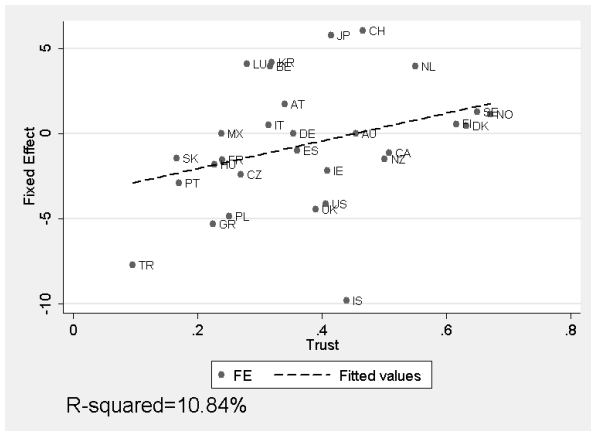

Figure 10: Religiosity

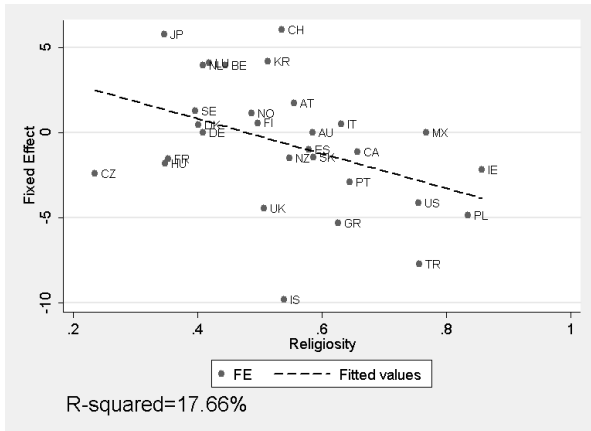

\section{Conclusion}

According to Holinski et al. (2012) and Jaumotte and Sodsriwiboon (2010) cross-country heterogeneity in private saving behavior is the prime driver of 
the macroeconomic imbalances that emerged in the eurozone in the period 1999-2007. In this paper, we empirically investigate the determinants of cross-country saving to shed more light on the heterogeneity between countries in general and between eurozone countries in particular. Since standard macroeconomic factors behind saving behavior fail to provide a fully satisfactory explanation of cross-country heterogeneity, we add a few institutional and cultural variables to our analysis. In order to check the impact of these factors, we first use pooled OLS regression on a set of thirty OECD countries for the period 1990-2010. Additional explanatory variables of private saving, next to the usual macroeconomic variables are three cultural variables: thrift,trust and religiosity. These indicators of cultural and institutional country-specific characteristics are constructed through aggregation of individual responses to relevant questions from the European and World value surveys. It turns out that thrift and trust are significant and have the expected sign when included in the model that substitute the country fixed effects for the cultural variables. Although religiosity is significant under the same setting, it has an unexpected sign.

Additionally, we do a panel country-fixed effects estimation on the same group of countries and subsequently relate the estimated fixed effects to the three cultural variables. The results give a picture that is consistent with the pooled OLS results. First, we observe a clustering of estimated country fixed effect along well-known geographical and institutional lines. It is possible to distinguish an Asian group, an Anglo-saxon group, a group of Northern European countries including the Scandinavian countries and a Southern European group. Simple regression analysis confirms the existence of significant relations between the estimated fixed effects and the three cultural variables both for the group of thirty OECD countries as a whole and for the Eurozone countries alone.

From our results we cautiously conclude that cross-country heterogeneity cannot be fully understood when disregarding cultural and historical factors. For private saving we find a clear and plausible relationship with cultural variables. More research is necessary to investigate this relationship in-depth, using a broader set of institutional and cultural variables as well as more sophisticated estimation techniques. 


\section{Appendix}

Data Sources

Table A.1: Country Codes

\begin{tabular}{llllll}
\hline Country & Code & Country & Code & Country & Code \\
\hline Australia & AU & Hungary & HU & Norway & NO \\
Austria & AT & Iceland & IS & Poland & PL \\
Belgium & BE & Ireland & IE & Portugal & PT \\
Canada & CA & Italy & IT & Slovakia & SK \\
Czech Republic & CZ & Japan & JP & Spain & ES \\
Denmark & DK & Korea & KR & Sweden & SE \\
Finland & FI & Luxembourg & LU & Switzerland & CH \\
France & FR & Mexico & MX & Turkey & TR \\
Germany & DE & Netherlands & NL & United Kingdom & UK \\
Greece & GR & New Zealand & NZ & United States & US \\
\hline
\end{tabular}

Table A.2: Data Sources

\begin{tabular}{ll}
\hline Variable & Source \\
\hline Saving & AMECO and WorldBank \\
Government Saving & AMECO and IMF \\
Government Budget & AMECO and IMF \\
Private Saving & AMECO, IMF and WorldBank \\
Dependency Ratio & AMECO \\
Net Foreign Assets & AMECO and Lane and Milesi-Ferretti (2007) \\
Real Disposable Income & AMECO \\
Real GDP Growth & AMECO \\
Inflation & AMECO, IMF and World Bank \\
Private Investment & AMECO \\
Current Account & AMECO \\
\hline
\end{tabular}




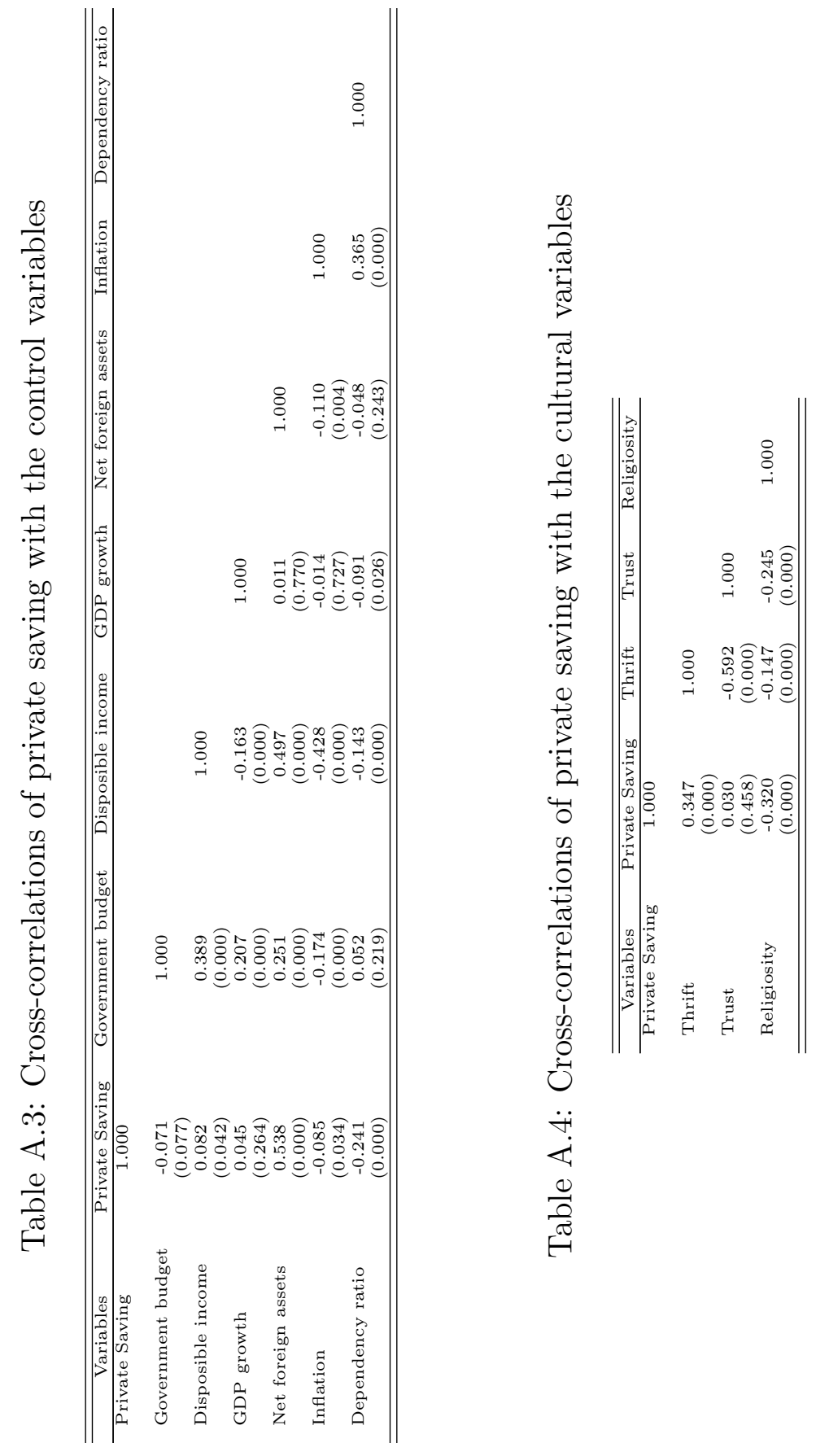




\section{References}

Acemoglu, D., Johnson, S., Robinson, J., 2001. The colonial origins of comparative development: An empirical investigation. The American Economics Review 91, 1369-1401.

Al-Awad, M., Elhiraika, A., 2003. Cultural effects and savings: Evidence from immigrants to the united arab emirates. The Journal of Development Studies 39 (5), 139-151.

Algan, Y., Cahuc, P., 2007. Social Attitudes and Economic Development: An Epidemiological Approach. Centre for Economic Policy Research.

Algan, Y., Cahuc, P., 2010. Inherited trust and growth. The American Economic Review 100 (5), 2060-2092.

Barro, R., McCleary, R., 2003. Religion and economic growth. American Sociological Review 68 (5), 760-781.

Beugelsdijk, S., Maseland, R., 2011. Culture in economics. Cambridge: Cambridge University Press.

Carroll, C., Rhee, B., Rhee, C., 1994. Are there cultural effects on saving? some cross-sectional evidence. The Quarterly Journal of Economics 109 (3), 685 .

Carroll, C., Rhee, B., Rhee, C., 1999. Does cultural origin affect saving behavior? evidence from immigrants. Economic Development and Cultural Change 48 (1), 33-50.

De Serres, A., Pelgrin, F., 2002. The decline in private saving rates in the 1990s in oecd countries: how much can be explained by non-wealth determinants? OECD Economics Working Paper.

Demirguc-Kunt, A., Levine, R., 2004. Financial structure and economic growth: A cross-country comparison of banks, markets, and development. MIT press.

Edwards, S., 1996. Why are latin america's savings rates so low? an international comparative analysis. Journal of Development Economics 51 (1), $5-44$. 
Efendic, A., Pugh, G., Adnett, N., 2010. Institutions and economic performance: A meta-regression analysis. European Journal of Political Economy.

Fernández, R., 2010. Does culture matter? Tech. rep., National Bureau of Economic Research.

Guiso, L., Sapienza, P., Zingales, L., 2003. People's opium? religion and economic attitudes. Journal of Monetary Economics 50, 225-282.

Guiso, L., Sapienza, P., Zingales, L., 2006. Does culture affect economic outcomes? Journal of Economics Perspectives 20 (2), 23-48.

Haque, N., Pesaran, M., Sharma, S., 1999. Neglected heterogeneity and dynamics in cross-country savings regressions. No. 99-128. International Monetary Fund.

Hofstede, G., 2001. Culture's consequences: Comparing values, behaviors, institutions and organizations across nations. Sage Publications, Incorporated.

Holinski, N., Kool, C., Muysken, J., 2012. Persistent macroeconomic imbalances in the euro area: causes and consequences. Federal Reserve Bank of St. Louis Review 94 (1).

Hondroyiannis, G., 2006. Private saving determinants in european countries: A panel cointegration approach. The Social Science Journal 43 (4), 553569.

Hussein, K., Thirlwall, A., 1999. Explaining differences in the domestic savings ratio across countries: a panel data study. The Journal of Development Studies 36 (1), 31-52.

Jaumotte, F., Sodsriwiboon, P., June 2010. Current account imbalances in the southern euro area. IMF Working Paper WP/10/139.

Kessler, D., Perelman, S., Pestieau, P., 1993. Savings behavior in 17 oecd countries. Review of Income and Wealth 39 (1), 37-49.

Knack, S., Keefer, P., 1997. Does social capital have an economic payoff? a cross-country investigation. The Quarterly journal of economics 112 (4), $1251-1288$. 
Lane, P., Milesi-Ferretti, G., 2007. The external wealth of nations mark ii: Revised and extended estimates of foreign assets and liabilities. Journal of International Economics 73, 223-250.

Loayza, N., Schmidt-Hebbel, K., Servén, L., 2000. What drives private saving across the world? Review of Economics and Statistics 82 (2), 165-181.

Mangeloja, E., 2005. Economic growth and religious production efficiency. Applied Economics 37 (20), 2349-2359.

Masson, P., Bayoumi, T., Samiei, H., 1998. International evidence on the determinants of private saving. The World Bank Economic Review 12 (3), 483-501.

McCleary, R., Barro, R., 2006. Religion and economy. The Journal of Economic Perspectives 20 (2), 49-72.

North, D., 1992. Institutions and economic theory. The American Economist $36(1), 3-6$.

Ramajo, J., García, A., Ferré, M., 2006. Explaining aggregate private saving behaviour: new evidence from a panel of oecd countries. Applied Financial Economics Letters 2 (5), 311-315.

Schmidt-Hebbel, K., Webb, S., Corsetti, G., 1992. Household saving in developing countries: first cross-country evidence. The World Bank Economic Review 6 (3), 529-547.

Tabellini, G., 2007. Culture and institutions. CEPR Discussion Paper No. DP6589.

Tabellini, G., 2010. Culture and institutions: economic development in the regions of europe. Journal of the European Economic Association 8 (4), $677-716$. 